\title{
ASSOCIATION OF THE ADRB2 GENE POLYMORPHIC VARIANT C79G (rs1072714) WITH THE COURSE OF CHRONIC OBSTRUCTIVE PULMONARY DISEASE IN OBESE AND NON-OBESE PATIENTS
}

\author{
Ganna Stupnytska ${ }^{1}$, Nataliya Gorovenko ${ }^{2}$, Svetlana Podolska ${ }^{3}$, Zoriana $\mathrm{Kit}^{4}$, \\ Michael Sheremet $^{5}$, Anatoliy Kovtun ${ }^{6}$, Olga Nesterovska ${ }^{7}$
}

\begin{abstract}
:
Introduction: Attention has been paid to studying the role of the sympathetic nervous system and polymorphism of the $\beta_{2}-$ adrenoceptor genes in the development of chronic obstructive pulmonary disease (COPD) in recent years, but the findings of the studies contradict each other.

Objective: To establish an association between the ADRB2 gene polymorphic variant C79G (rs1072714) in obese and nonobese COPD patients.

Methods: The study involved 48 obese COPD patients and 52 nonobese COPD patients. The ADRB2 gene polymorphic variant C79G (rs 1072714) was genotyped and assessed by the CAT test and the BODE index.

Results: It has been established that in obese COPD patients the CAT test was significantly higher in the genotype GG (24.25 $\pm 4.25)$ compared to those with obesity and the genotype CC and CG ( $\mathrm{p}<0.05)$. The BODE index was significantly $(\mathrm{p}<0.05)$ lower in obese COPD patients. A strong positive correlation between BMI and $\mathrm{FEV}_{1}(r=0.742, \mathrm{p}=0.014)$ in nonobese COPD patients with GG genotype has been found.

Conclusion: According to the CAT test, the quality of life in obese COPD patients with GG genotype is worse. The BODE index in obese COPD patients with CC and CG genotypes was significantly lower than in those without obesity. A strong positive correlation between $\mathrm{BMI}$ and $\mathrm{FEV}_{1}$ in COPD patients without obesity with GG genotype has been established.
\end{abstract}

UDC Classification: 616-001/-009; DOI: http://dx.doi.org/10.12955/cbup.v6.1278

Keywords: chronic obstructive pulmonary disease, obese, BODE, CAT

\section{Introduction}

Chronic Obstructive Pulmonary Disease (COPD) is a complex heterogeneous disease, the development of which is based on a genetic predisposition and environmental factors (GOLD, 2018).

The clinical and functional heterogeneity of patients with COPD in terms of the symptom severity, frequency and type of exacerbations, lung function, structural changes, local and systemic inflammation, as well as a response to a therapy have been proven (Barnes et al., 2009).

Twenty percent of smokers develop COPD primarily due to a genetic predisposition to the disease (GOLD, 2018). Today, the role of candidate genes in the development of COPD has been actively studied. In particular, in two meta-analyzes, the role of genes coding the synthesis of TNF $\alpha$, TGF $\beta_{1}$, glutathione-S-transferase $\mathrm{P}_{1}$ and $\mathrm{M}_{1}$, and superoxide dismutase 3 have been established (Hancock et al., 2010). Issac et al. (2014) studied the involvement of the gene polymorphism of the surfactant protein Drs2243639, IL-1 $\beta r s 16944$ and IL-1RNrs2234663 in the pathology. The role of $\alpha_{1}$-antitrypsin deficiency in the development of pulmonary emphysema and COPD has been clearly identified (GOLD, 2018).

\footnotetext{
${ }^{1}$ Department of Internal Medicine and Infectious Disease, Higher education institution in Ukraine "Bukovinian State Medical University”, Ukraine, dumanna77@gmail.com

${ }^{2}$ Department of Medical Genetics, National Medical Academy for Post-graduate Education named after P.L. Shupyk, Kyiv, Reference-centre for molecular diagnostic, Ministry of Public Health of Ukraine, Ukraine, medgen2010@ukr.net

${ }^{3}$ Department of Medical Genetics, National Medical Academy for Post-graduate Education named after P.L. Shupyk, Kyiv, Reference-centre for molecular diagnostic, Ministry of Public Health of Ukraine, Ukraine, medgen2010@ukr.net

4 Department of Family Medicine, Danylo Halytsky Lviv National Medical University, Ukraine, zoryana.kit27@gmail.com

${ }^{5}$ Department of Surgery, Higher education institution in Ukraine "Bukovinian State Medical University”, Ukraine, mihay171@gmail.com

${ }^{6}$ Department of Anesthesiology and Reanimatology, Higher education institution in Ukraine "Bukovinian State Medical University", Ukraine, mr.dok25@mail.com

${ }^{7}$ Department of Internal Medicine and Infectious Disease, Higher education institution in Ukraine "Bukovinian State Medical University", Ukraine, Olyanesterovska11@gmail.com
} 
Attention has been paid to studying the role of the sympathetic nervous system and the polymorphism of the $\beta_{2}$-adrenoceptor genes in the development of chronic obstructive pulmonary disease in recent years, but the findings of the studies contradict each other (Thomsen et al., 2012; Randhawa et al., 2014). The aim of this study is to establish an association between the ADRB2 gene polymorphic variant C79G (rs 1072714) in obese and non-obese COPD patients.

\section{Methods}

As a result of screening, 100 patients with COPD aged from 40 to 79 years (on average, $62.46 \pm 2.21$ ) were involved in the study. The inclusion criteria were: age more than 40 years; at least a 10 pack-year history of tobacco exposure; and Global Initiative for Obstructive Lung Disease (GOLD) stage criteria for COPD based on post-bronchodilator spirometry.

A questionnaire (the COPD Assessment Test (CAT)) was used to assess the symptoms.

Dyspnea level was measured by the modified Medical Research Council (mMRC) scale.

To assess exercise tolerance, a 6-minute walk test was conducted using the standard protocol (ATS statement guidelines, 2002).

To evaluate the severity of COPD, the BODE index was used. For the calculation of the BODE we used the model of Celli et al. (2004).

A bioelectrical impedance analysis was used to assess body composition. The measurements were carried out on a portable device VS-601 (TANITA, Japan). The body weight, BMI, muscle weight, fat weight percentage, visceral fat rate, metabolism in kcal, water $\%$ in the body, metabolic age, and \% of trunk fat were determined.

To carry out molecular genetic studies, the genomic DNA was isolated from the peripheral blood. Genotyping of the ADRB2 gene polymorphic variants C79G was performed according to the protocol byMartinez et al. (1997).

To establish the association of the ADRB2 gene polymorphic variant C79G (rs1072714) within the course of the disease, COPD patients were divided into two groups according to their body mass index: those with obesity (48 people) and those without obesity - 52 individuals. Underweight COPD patients were excluded from the study.

The statistical processing of the findings was performed using the statistical software package Statistica 10.0 StatSoftInc.

A correlation analysis was carried out using the nonparametric Spearman's rank correlation coefficient.

\section{Results and Discussion}

An analysis of the CAT questionnaire findings, the dyspnea score scale, the BODE index, and a 6minute walk test depending on the ADRB2 gene polymorphic variant C79G (rs1072714) (Table 1), was performed.

Table 1: Values of CAT test, dyspnea score scale, BODE index, a 6-minute walk test in obese and non-obese COPD patients depending on polymorphism C79G (rs1042714) of the ADRB2 gene

\begin{tabular}{|c|c|c|c|}
\hline Values & Genotype & Obese COPD patients & Nonobese COPD patients \\
\hline \multirow{3}{*}{$\begin{array}{l}\text { CAT-tests, } \\
\text { scores }\end{array}$} & $\mathrm{CC}$ & $13.93 \pm 1.61$ & $17.42 \pm 1.89$ \\
\hline & $\mathrm{CG}$ & $\begin{array}{l}19.72 \pm 1.21 \\
\mathrm{p}_{\mathrm{CC}}<0.01\end{array}$ & $20.14 \pm 1.60$ \\
\hline & GG & $\begin{array}{l}24.25 \pm 4.25 \\
\mathrm{p}_{\mathrm{CC}}<0.05\end{array}$ & $22.70 \pm 2.97$ \\
\hline \multirow{3}{*}{ dyspnea scale, scores } & $\mathrm{CC}$ & $2.47 \pm 0.17$ & $2.76 \pm 0.14$ \\
\hline & $\mathrm{CG}$ & $2.66 \pm 0.14$ & $2.86 \pm 0.13$ \\
\hline & GG & $2.75 \pm 0.48$ & $2.80 \pm 0.25$ \\
\hline \multirow{3}{*}{ BODE index, scores } & $\mathrm{CC}$ & $3.53 \pm 0.53$ & $5.09 \pm 0.39 *$ \\
\hline & $\mathrm{CG}$ & $4.28 \pm 0.37$ & $5.71 \pm 0.46^{*}$ \\
\hline & GG & $4.00 \pm 1.08$ & $4.40 \pm 0.75$ \\
\hline \multirow{3}{*}{ a 6 minute walk test } & $\mathrm{CC}$ & $346.33 \pm 25.94$ & $301.67 \pm 21.55$ \\
\hline & CG & $323.10 \pm 18.62$ & $280.71 \pm 17.87$ \\
\hline & GG & $287.50 \pm 39.45$ & $264.12 \pm 14.53$ \\
\hline
\end{tabular}


It has been established that in obese COPD patients the CAT test was significantly higher in those who are carriers of the $\mathrm{CC}$ and $\mathrm{CG}$ genotype $(\mathrm{p}<0.05)$. When comparing obese COPD patients and those without obesity, there were no significantly differences. There are no differences between the dyspnea scale (in scores) and a 6-minute walk test either.

The BODE index was lower ( $\mathrm{p}<0.05)$ in obese COPD patients $(30.6 \%$ in the CC genotype and $25 \%$ in the CG genotype). There were no significantly differences between the groups in the genotype GG.

Therefore, we have found that there were significant differences in obese COPD patients between genotypes and the highest total score of the CAT test was in the genotype GG.

The BODE integral index was significantly lower in obese COPD patients than in those without obesity who are carriers of the CC and CG genotype. In the genotype GG there were no significantly differences between the group of obese and non-obese patients.

We carried out a correlation analysis between the values of bioelectrical impedance analysis and those of spirometry depending on the ADRB2 gene polymorphism (C79G) (Table 2, Table 3). There was a significant inverse proportional relationship between the level of visceral fat and the forced expiratory volume during the first second of the expiration $\left(\mathrm{FEV}_{1}\right)(\mathrm{r}=-0.570, \mathrm{p}=0.007), \mathrm{FEV}_{6}(\mathrm{r}=-0.434, \mathrm{p}=$ $0.05), \mathrm{FEV}_{1} / \mathrm{FVC}(\mathrm{r}=-0.486, \mathrm{p}=0.025), \mathrm{FEV}_{1} / \mathrm{FEV}_{6}(\mathrm{r}=-0.485, \mathrm{p}=0.026)$ in non-obese COPD patients with the $\mathrm{CC}$ genotype.

A negative correlation in this group of patients was also observed in pairs of $\%$ of body fat content $\mathrm{FEV}_{1} / \mathrm{FVC}(\mathrm{r}=-0.496, \mathrm{p}=0.022), \%$ of body fat content- $\mathrm{FEV}_{1} / \mathrm{FEV}_{6}(\mathrm{r}=-0.509, \mathrm{p}=0.018)$. According to the genotype GG in non-obese COPD patients, a strong positive correlation between BMI and $\mathrm{FEV}_{1}$ should be noted $(\mathrm{r}=0.742, \mathrm{p}=0.014)$.

Obesity is associated with numerous lung problems, faster $\mathrm{FEV}_{1}$ reduction, development of sleep apnea syndrome (Cecere et al., 2011; Vozoris et al., 2012; Melo et al., 2014). In COPD, obesity demonstrates itself by mixed effects, along with reduced exercise tolerance and lower quality of life, there is less severe airflow obstruction and reduced mortality (Franssen et al., 2008; Blum et al., 2011; Katz et al., 2016; Lambert et al., 2017).

The dependence of the onset and development of COPD on the ADRB2 gene polymorphism was studied as well (Nielson et al., 2017). Contradictory results were obtained. Some studies showed the dependence of the onset of the disease and the effect on the severity of the flow of the ADRB2 gene polymorphism (Konno et al., 2011). Other studies indicated a lack of the association (Mokry et al., 2008; Kim et al., 2009).

Various results have been obtained regarding the dependence of this polymorphism on obesity development (Zhang et al., 2014; Saliba et al., 2014; Aplalasamy et al., 2015; Leonska-Duniec et al., 2016).

In our previous studies the association of the ADRB2 gene polymorphic variant C79G (rs1072714) with the development of obesity in COPD patients was shown (Gorovenko et al., 2014; Gorovenko et al., 2015).

In this work we studied the CAT test and the integral BODE index of COPD patients with and without obesity depending on the ADRB2 gene polymorphic variant C79G (rs1072714).

According to GOLD recommendations, the CAT test is used to assess the COPD effect on patients' quality of life (GOLD, 2018). This value was studied in different populations of patients depending on age, sex, status of smoking, in persons with non-diagnosed COPD and COPD severity (Gupta et al., 2016). A deterioration in the health status with an increase in the severity of obstruction and the frequency of exacerbation was established (Koniskaet al., 2015; Lopez-Campos et al., 2015; GarciaSidro et al., 2015; Srivastava et al., 2017).

It has been found that in obese COPD patients the CAT test had differences in the genotypes CC, CG and GG. In those who are carriers of the GG genotype this value was the highest one.

The obtained data may be indicative of the fact that in obese COPD patients with the GG genotype a subjective evaluation of the disease is worse.

As many studies (Celli et al., 2008; Cote et al., 2009; Corlateanu et al., 2016) and recommendations of GOLD indicate (GOLD, 2018), one cannot estimate the severity and prognosis of COPD based on one value. The BODE integral index proposed by Celli at al. (2004) as a prognostic index has recently been 
used to assess the severity of the disease and the effectiveness of the drug and pulmonary rehabilitation programs (Ong et al., 2005; Kavoura et al., 2016; Nakato et al., 2016).

According to our study, the BODE index had a significant difference between the groups of patients with and without obesity in CC and CG genotypes and was lower in the group of obese patients. In the homozygous GG genotype, the severity of the disease (according to the BODE index) did not depend on the presence of the concomitant obesity.

Some studies investigated the relationship between the spirometry parameters and BMI (van den Borst et al., 2011; Abston et al., 2017). Underweight COPD patients showed worse spirometry values (Eriksson et al., 2016).

Overweight and obese COPD patients had less severe airflow obstruction than underweight patients. A low BMI in COPD patients is known to be a mortality predictor (Landbo et al., 1999; Hallin et al., 2007). Therefore, it is important to study the structure of the body, namely the muscle mass in patients with COPD.

This work studied the correlations between the spirometry values and those of bioelectrical impedance analysis in COPD patients without and with obesity depending on the ADRB2 gene polymorphic variant C79G (rs1072714).

It was determined that in non-obese COPD patients there was a strong positive correlation between BMI and $\mathrm{FEV}_{1}$ in the GG genotype. This is important in order to manage this contingent of patients in the future. Such patients should monitor the spirometry and bioelectrical impedance analysis values, since further reduction of BMI may affect the life expectancy for these patients.

\section{Conclusion}

It has been established that the impact of COPD on the quality of life of patients according to the CAT test is more pronounced in obese COPD patients with the GG genotype. The BODE index in obese COPD patients with the CC and CG genotypes was significantly lower than in those without obesity. In patients with the homozygous genotype GG, the more severe course of the disease did not depend on the presence of obesity. A strong positive correlation between the BMI and the $\mathrm{FEV}_{1}$ in non-obese COPD patients with the GG genotype was determined.

\section{References}

Abston, E., Comellas, A., Reed, R., Kim, V., Wise, R., Brower, R., Fortis, S., Beichel, R., Bhatt, S., Zabner, J., Newell, J., Hoffman, E., Eberlein, M. (2017). Higher BMI is associated with higher expiratory airflow normalized for lung volume (FEF25-75/FVC) in COPD. BMJ open Respiratory Research, 4, 000231. doi: 10.1136/bmjresp-2017-000231.

Aplalasamy, Y., Ming, M., Rampal, S., Bulgiba, A., Mohamed, Z. (2015). Gender-dependent association of a $\beta(2)$-adrenergic gene variant with obesity parameters in Malaysian Malays. Asia Pacific Journal of Public Health, 27(2), NP154-165. doi: 10.1177/1010539511430250.

ATS Committee on Proficiency Standards for Clinical Pulmonary Function Laboratories: ATS statement guidelines for the six-minute walk test. (2002). American Journal Respiratory Critical Care Medicine, 66, 111-117.

Barnes, P., Celli, B. (2009). Systemic manifestations and comorbidities of COPD. European Respiratory Journal, 33 (5), 1165-1185.

Blum, A., Simsolo, C., Sirchan, R., Haiek, S. (2011). "Obesity paradox" in chronic obstructive pulmonary disease. Israel Medical Association Journal, 13(11), 672-675.

Cecere, L., Littman, A., Slatore, C. (2011). Obesity and COPD: associated symptoms, health-related quality of life, and medication use], including increased prevalence and severity of asthma. COPD, 8, 275-284.

Celli, B., Cote, C., Lareau, S., Meek, P. (2008). Predictors of survival in COPD: more than just the FEV 1 . Journal of Respiratory Medicine, 102(1), S27-35.

Celli, B., Cote, C., Marin, J., Casanova, C., Montes de Osa, M., Mendez, R., Plata, V., Cabral, H. (2004). The body-mass index, airflow obstruction, dyspnea, and exercise capacity index in chronic obstructive pulmonary disease. The New England Journal of Medicine, 350, 1005-1012.

Corlateanu, A., Botnaru, V., Covantev, S., Dumitru, S., Siafakas, N. (2016)/ Predicting health-related quality of life in patients with chronic obstructive pulmonary disease: the impact of age. Respiration, 92, 229-234. doi: 10.1159/000448625.

Cote, C., Celli, B. (2009). BODE index: a new tool to stage and monitor progression of chronic obstructive pulmonary disease. Pneumonologia Alergologia Polska, 77, 305-313.

Franssen, F., O’Donnell, D., Goossens, G., Blaak, E., Schols, A. (2008). Obesity and the lung: 5 Obesity and COPD. Thorax, 63, 1110-1117. doi: 10.1136/thx.2007.086827.

Garcia-Sidro, P., Naval, E., Rivera, C., Bonnin-Vilaplana, M., Garcia-Rivero, J., Herrejon, A., Malo de Molina, R., Marcos, P., Mayoralas-Alises, S., Ros, J., Valle, M., Esquinas, C., Barrecheguren, M., Miravitlles, M. (2015). The CAT (COPD 
Assessment test) questionnaire as a predictor of the evolution of severe COPD exacerbations. Respiratory Medicine, 109(12), 1546-1552. doi: 10.1016/j.rmed.2015.10.011.

Global strategy for the diagnosis, management, and prevention of chronic obstructive pulmonary disease (2018 report) / 2018 Global Initiative for Chronic Obstructive Lung Disease, Inc. Retrieved from http://goldcopd.org/wpcontent/uploads/2017/11/GOLD-2018-v6.0-FINAL-evised-20-Nov_WMS.pdf.

Gorovenko, N., Stupnytska, G., Podolska, S. (2014). Polymorphic variants of ADRB2, NR3C1, VDR1 genes as possible predictors of efficacy of combined therapy LABA+ICS in patients with chronic obstructive pulmonary disease. The Pharma Innovation Journal, №3(8), 10-14.

Gorovenko, N., Stupnytska, G., Podolska, S. (2015). Polymorphic variants of genes ADRB2, NR3C1, MDR1 in patients with chronic obstructive pulmonary disease and obesity. European Respiratory Journal, 46(59), PA1232.

Gupta, N., Pinto, L., Benedetti, A., Li, P., Tan, W., Aaron, S., Chapman, K., FitzGerald, M., Hernandez, P., Marciniuk, D., Maltais, F., O’Donnell, D., Sin, D., Walker, B., Bourbeau, J. (2016). The COPD Assessment test. Chest, 150(95), 1069-1079. Hallin, R., Gudmundsson, G., Ulrik, C. (2007). Nutritional status and long-term mortality in hospitalized patients with chronic obstructive pulmonary disease (COPD). Respiratory Medicine, 101, 1954-1960.

Hancock, D., Eijgelsheim, M., Wilk, J., Gharib, S., Loehr, L. (2010). Meta-analyses of genome-wide association studies identify multiple loci associated with pulmonary function. Nature Genetics, 42, 45-52.

Issac, M., Ashur, W., Mousa, H. (2014). Genetic Polymorphisms of Surfactant Protein D rs2243639, Interleukin (IL)-1 $\beta$ rs 16944 and IL-1RN rs2234663 in Chronic Obstructive Pulmonary Disease, Healthy Smokers, and Non-Smokers [Abstract]. Molecular Diagnosis \& Therapy, 18(3), 343-354. doi: 10.1007/s40291-014-0084-5.

Katz, P., Iribarren, C., Sanchez, G., Blanc, P. (2016). Obesity and functioning among individuals with chronic obstructive pulmonary disease (COPD). COPD, 13(3), 352-359.

Kavoura, P., Kostikas, K., Tselebis, A., Bratis, D., Kosmas, E., Alchanatis, M., Koulouris, N., Bakakos, P., Loukides, S. (2016). Changes in BODE quartiles after pulmonary rehabilitation do not predict 2-year survival in patients with COPD. Journal of Cardiopulmonary rehabilitation and preventation, 36(1), 62-67. doi:10.1097/HCR.0000000000000157.

Kim, W., Hersh, C., DeMeo, D., Reilly, J., Silverman, E. (2009). Genetic association analysis of COPD candidate genes with bronchodilator responsiveness. Respiratory Medicine, 103, 552-557, https://doi.org/10.1016/j.rmed.2008.10.025.

Koniska, M., Salhi, H., Lahlou, A., Rashid, N., Hasnaoui, A. (2015). Distribution of body mass index among subjects with COPD in the Middle East and North Africa region: data from the BREATHE study. International Journal of COPD, 10, 1685-1694.

Konno, S., Makita, H., Hasegawa, M., Nusuhara, Y., Nagai, K., Betsuyaku, T. (2011). Beta2-adrenergic receptor polymorphisms as a determinant of preferential bronchodilator responses to $\beta 2$-agonist and anticholinergic agents in Japanese patients with chronic obstructive pulmonary disease. Pharmacogenet. Genomics, 21, 687-693, https://doi.org/10.1097/FPC.0b013e328349aa1.

Lambert, A., Putcha, N., Drummond, M., Boriek, A., Hanania, N., Kim, V., Kinney, G., McDonald, M., Brigham, E., Wise, R., McCormack, M., Hanse. N. (2017). Obesity Is Associated With Increased Morbidity in Moderate to Severe COPD. Chest, 151(1), 68-77.

Landbo, C., Prescott, E., Lange, P. (1999). Prognostic value of nutritional status in chronic obstructive pulmonary disease. American Journal Respiratory Critical Care Medicine, 160, 1856-1861.

Leonska-Duniec, A., Ahmetov, I., Zmijewski, P. (2016). Genetic variants influencing effectiveness of exercise training programmes in obesity - an overview of human studies. Biology of Sport, 33(3). 207-214. doi: 10.5604/20831862.1201052.

Lopez-Campos, J., Fernandez-Villar, A., Calero-Acuna, C., Represas-Represas, C., Lopez-Ramirez, C., Fernandez, V., SolerCataluna, J., Casamor, R. (2015). Evaluation of the COPD assessment test and GOLD patient types: a cross-sectional analysis. International Journal of COPD, 10, 975-984.

Martinez, F., Graves, P., Baldini, M., Solomon, S., Erickson, R. (1997). Association between genetic polymorphisms of the beta2-adrenoceptor and response to albuterol in children with and without a history of wheezing. Journal Clinical Investigation, 100(12), 3184-3188.

Melo, L., Silva, M., Calles, A. (2014). Obesity and lung function: a systematic review. Einstein (Sao Paulo), 21(1), 120-125., Zammit, C., Liddicoat, H., Moonsie, I., Makker, H. (2010). Obesity and respiratory diseases. International Journal of General Medicine, 3, 335-343.

Mokry, M., Joppa, P., Slaba, E., Zidzik, J., Habalova, V., Kluchova, Z., (2008). Beta2-adrenergic receptor haplotype and bronchodilator response to salbutamol in patients with acute exacerbation of COPD. Medical Science Monitor, 14, CR392C398.

Nakato, A., Galhardo, M., Nakato, D., Ramires, B., Faganello, M. (2016). Pulmonary rehabilitation and BODE index in patients with COPD. SM Journal of Pulmonary Medicine, 2(2), 1018

Nielson, A., Jensen, C., Arredouani, M., Dahl, R., Dahl, M. (2017). Variants of the ADRB2 Gene in COPD: Systematic Review and Meta-Analyses of Disease Risk and Treatment Response. COPD, 14(4), 451-460. doi: 10.1080/15412555.2017.1320370.

Ong, K., Earnest, A., Lu, S. (2005). A multidimensional grading system (BODE index) as predictor of hospitalization for COPD. Chest, 128, 3810-3816. 
Randhawa, I., Pham, A., Klaustermeyer, W., Yusin, J. (2014). No Correlation between Beta2-Adrenergic Receptor Polymorphisms and the Severity and Clinical Control of Geriatric Asthma and COPD. Journal of Allergy \& Therapy, 5, 196. This article is available from: doi: 10.4172/2155-6121.1000196.

Saliba, L., Reis, R., Brownson, R., Hino, A., Tureck, L., Valko, C., Souza R., Furtado-Alle, L. (2014). Obesity-related gene ADRB2, ADRB3 and GHRL polymorphisms and the response to a weight loss diet intervention in adult women. Genetics and Molecular Biology, 37, 15-22.

Srivastava, A., Tripathi, S., Srivatsava, M., Kumar, V. (2017). To study the correlation between spirometry and CAT score in patients of COPD. Journal Evolution Medical Dental Science, 6(20). 1636-1638. doi:10.14260/Jemds/1017/358

Thomsen, M., Nodestgaard, B., Sethi, A., Tybjarg-Hansen, A., Dahl, M. (2012). $\beta_{2}$-adrenergic receptor polymorphisms, asthma and COPD: two large population-based studies. European Respiratory Journal, 39, 558-566. doi:10.1183/09031936.00023511/.

van den Borst, B., Koster, A., Yu, B. (2011). Is age-related decline in lean mass and physical function accelerated by obstructive lung disease or smoking? Thorax, 66, 961-969.

Vozoris, N., O'Donnell, D. (2012). Prevalence, risk factors, activity limitation and health care utilization of an obese, population-based sample with chronic obstructive pulmonary disease. Canadian Respiratory Journal, 19, e18-e24.

Zhang, H., Wu, J., Yu, L. (2014). Association of Gln27Glu and Arg16Gly polymorphisms in beta2-adrenergic receptor gene with obesity susceptibility: a meta-analysis. PLOS ONE, 9(6), e100489. doi: 10.1371/journal.pone.0100489. 